\title{
Anabases
}

ANABASES Traditions et réceptions de l'Antiquité

$25 \mid 2017$

Varia

\section{Hans-Christian GÜNTHER (dir.), Augustus und Rom : 2000 Jahre Danach}

Cyrielle Landrea

\section{OpenEdition}

Journals

Édition électronique

URL : http://journals.openedition.org/anabases/6135

DOI : 10.4000/anabases. 6135

ISSN : 2256-9421

Éditeur

E.R.A.S.M.E.

Édition imprimée

Date de publication : 1 avril 2017

Pagination : 286-287

ISSN : 1774-4296

\section{Référence électronique}

Cyrielle Landrea, « Hans-Christian güntheR (dir.), Augustus und Rom : 2000 Jahre Danach», Anabases [En ligne], 25 | 2017, mis en ligne le 01 avril 2017, consulté le 20 janvier 2021. URL : http://

journals.openedition.org/anabases/6135; DOI : https://doi.org/10.4000/anabases.6135

Ce document a été généré automatiquement le 20 janvier 2021

(c) Anabases 


\title{
Hans-Christian GÜNTHER (dir.), Augustus und Rom : 2000 Jahre Danach
}

\author{
Cyrielle Landrea
}

\section{RÉFÉRENCE}

Hans-Christian GÜNTHER (dir.), Augustus und Rom : 2000 Jahre Danach

Nordhausen, Verlag T. Bautz, Studia Classica e Mediaevalia 9, 2015, 348 p., 60 euros / ISBN 978-3959480000

1 La commémoration des deux mille ans de la mort d'Auguste fut accompagnée d'une multitude de colloques et de journées d'étude. Ces actes s'inscrivent bien dans cette vague d'engouement pour le principat d'Auguste. La journée d'étude intitulée Augusto e Roma, 2000 anni dopo se déroula le 19 septembre 2014 à Rome. La rapidité d'édition des actes est d'ailleurs assez remarquable, mais au détriment de relectures, puisque John Scheid se voit appeler Scheidt dans le sommaire. En outre ce manque de relecture se remarque par la présence significative de coquilles. Par exemple (p. 135), F. Hurlet et B. Mineo se voient appeler dans une bibliographie : «Murlet, M / E. Minco E. ».

2 Quoi qu'il en soit Augustus und Rom : 2000 Jahre Danach se veut singulier dans cette vague de commémoration, en mêlant pluralité des approches antiques (artistique, historique, juridique, littéraire et poétique) et réception philosophique avec Hegel et Heidegger. Volontairement éclectique, ce symposion réunit également des collègues d'horizons divers (Allemagne, France, Espagne, Italie et Suisse).

3 La première contribution de H.-C. Günther (Augustus nach 2000 Jahren, p. 15-45) peut être considérée comme une introduction. Selon lui, la figure toujours actuelle d'Auguste est trop importante pour être laissée aux fascistes, car elle a influencé la culture et l'histoire européennes. Pourtant Auguste est très souvent connoté et il rappelle que l'œuvre magistrale de R. Syme occupe une place importante dans la controverse. La vision du princeps est alors inséparable de la montée des totalitarismes et de la Seconde Guerre mondiale. L'empreinte politique augustéenne a également inspiré une 
multitude de gouvernants, comme Louis XIV. L'auteur ne ressent aucune gêne en comparant Auguste à Staline ou Mao, sous prétexte qu'ils étaient " tous impitoyables et sans scrupules ». Par ailleurs l'analyse des " empires » de l'époque contemporaine et de leurs rapports avec la Rome augustéenne ne convainc pas forcément.

Il programma augusteo nel IV libro delle elegie di Properzio de P. Fedeli (p. 47-66) met en avant les polémiques liées à la politique augustéenne, en rappelant des éléments déjà bien connus et il replace l'œuvre de Properce dans la poésie contemporaine. Le Princeps a ainsi préféré la continuité à la rupture ; un trait aussi visible dans la poésie élégiaque où le prince est représenté comme un innovateur ancré dans la tradition. La poésie augustéenne est encore au cœur du long article (p. 67-136) de H.-P. Syndikus (Das Wesen der augusteischen Dichtung). Cette contribution permet de donner une vision très large de la poésie et de ses rapports avec le pouvoir augustéen et la pensée grecque d'une part, mais aussi de revenir sur les interprétations des Modernes. Le poète se considérait alors souvent comme un uates. En outre la taille considérable des compositions mettant l'accent sur les origines contribue à une nouvelle appréciation des traditions romaines sans omettre le poids de l'Italie. H.-C. Günther s'inscrit ensuite dans la continuité de l'article précédent (Augustus und die Dichtung, p.137-162) et rappelle une évidence : tous les poètes n'étaient pas politisés. L'article accumule les défauts : approches psychologiques, jugements de valeur douteux, parallèles anachroniques et malvenus (John Wayne, JR de Dallas)... La bibliographie compte trente titres dont la moitié est consacrée à la production de l'auteur. D. Liebs (Augustus schützt das Recht, p. 163-215) s'intéresse aux formes législatives développées par Auguste pour protéger le droit dans toute sa diversité : droit constitutionnel, droit pénal... Le propos est clair et organisé. L'analyse est détaillée et les mesures sont replacées dans une chronologie précise, en renvoyant aux sources antiques. Ensuite J. Scheid (Auguste et la religion, p. 217-242) précise que les croyances d'Auguste n'importent guère et que nous manquons de sources. L'intérêt porte sur la "politique religieuse ", même si l'auteur rappelle justement l'anachronisme de cette expression. Le ritualisme ne doit pas être sousestimé et Auguste redonna à la respublica sa forme religieuse antérieure. L'analyse est claire et précise ; elle s'impose pour une première approche de la religion à l'époque augustéenne. Après des précisions bien connues sur la statue de l'Auguste Prima Porta, A. Stavru (Graphike, andriantopoiia e thorakopoiia nell'Augusto di Prima Porta. Una lettura ecfrastica di Xenoph., Mem. III 10, p. 243-280) analyse la place de l'art dans la pensée grecque, particulièrement chez Xénophon, et son influence sur la conception de cette statue. Cette lecture ekphrastique manque hélas de précision. V. Rocco Lozano ( $L a$ Romanitas nella filosofia di Hegel, p. 281-313) ne s'intéresse pas à la figure augustéenne, mais analyse dans un propos structuré les allusions au monde romain dans l'œuvre hégélienne. L'article suivant de I. de Gennaro et G. Zaccaria (EYAAIMONIA FELICITAS BEATITUDO : La romanità allo specchio della Seinsfrage. Heidegger e Roma, p. 315-348) traite peu du princeps hormis pour des points ponctuels comme sa felicitas.

5 L'ensemble manque hélas de cohérence. De surcroît il apparaît difficile de comprendre l'esprit de cette journée d'étude, au-delà de la juxtaposition d'interventions de taille et de qualité inégales. Les comparaisons récurrentes ou les allusions pléthoriques aux régimes totalitaires $\mathrm{du} \mathrm{xx}^{\mathrm{e}} \mathrm{s}$. sont plus que lassantes. Oui il est possible de traiter l'Histoire augustéenne sans tenter des parallèles parfois très hasardeux. Toutefois de nombreux points positifs peuvent être mis en avant : quelques articles sont brillants et chaque article est assorti d'une bibliographie sélective fort commode. 


\section{AUTEURS}

\section{CYRIELLE LANDREA}

Laboratoire ANHIMA UMR 8210

cyrielle.landrea@orange.fr 